BNL-79626-2007-CP

\title{
High performance EBIS for RHIC
}

\section{J. Alessi, E. Beebe, O. Gould, A. Kponou, R. Lockey, A. Pikin, D. Raparia, J. Ritter, L. Snydstrup}

Presented at the $22^{\text {nd }}$ Particle Accelerator Conference (PAC'07)

Albuquerque, New Mexico

June 25-29, 2007

\section{Collider-Accelerator Department}

\author{
Brookhaven National Laboratory \\ P.O. Box 5000 \\ Upton, NY 11973-5000 \\ www.bnl.gov
}

Notice: This manuscript has been authored by employees of Brookhaven Science Associates, LLC under Contract No. DE-AC02-98CH10886 with the U.S. Department of Energy. The publisher by accepting the manuscript for publication acknowledges that the United States Government retains a non-exclusive, paid-up, irrevocable, world-wide license to publish or reproduce the published form of this manuscript, or allow others to do so, for United States Government purposes.

This preprint is intended for publication in a journal or proceedings. Since changes may be made before publication, it may not be cited or reproduced without the author's permission. 


\section{DISCLAIMER}

This report was prepared as an account of work sponsored by an agency of the United States Government. Neither the United States Government nor any agency thereof, nor any of their employees, nor any of their contractors, subcontractors, or their employees, makes any warranty, express or implied, or assumes any legal liability or responsibility for the accuracy, completeness, or any third party's use or the results of such use of any information, apparatus, product, or process disclosed, or represents that its use would not infringe privately owned rights. Reference herein to any specific commercial product, process, or service by trade name, trademark, manufacturer, or otherwise, does not necessarily constitute or imply its endorsement, recommendation, or favoring by the United States Government or any agency thereof or its contractors or subcontractors. The views and opinions of authors expressed herein do not necessarily state or reflect those of the United States Government or any agency thereof. 


\title{
HIGH PERFORMANCE EBIS FOR RHIC*
}

\author{
J. Alessï, E. Beebe, O. Gould, A. Kponou, R. Lockey, A. Pikin, D. Raparia, J. Ritter, L. Snydstrup, \\ BNL, Upton, NY 11973 U.S.A.
}

\section{Abstract}

An Electron Beam Ion Source (EBIS), capable of producing high charge states and high beam currents of any heavy ion species in short pulses, is ideally suited for injection into a synchrotron. An EBIS-based, high current, heavy ion preinjector is now being built at Brookhaven to provide increased capabilities for the Relativistic Heavy Ion Collider (RHIC), and the NASA Space Radiation Laboratory (NSRL). Benefits of the new preinjector include the ability to produce ions of any species, fast switching between species to serve the simultaneous needs of multiple programs, and lower operating and maintenance costs. A state-of-the-art EBIS, operating with an electron beam current of up to $10 \mathrm{~A}$, and producing multi-milliamperes of high charge state heavy ions, has been developed at Brookhaven, and has been operating very successfully on a test bench for several years. The present performance of this highcurrent EBIS is presented, along with details of the design of the scaled-up EBIS for RHIC, and the status of its construction. Other aspects of the project, including design and construction of the heavy ion RFQ, Linac, and matching beamlines, are also mentioned.

\section{INTRODUCTION}

At BNL a new heavy ion preinjector, based on an EBIS source, is being constructed. There are considerable advantages to the use of an EBIS+linac-based preinjector instead of the present Tandem Van de Graaffs for injection of beams into the Booster synchrotron for RHIC and the NASA Space Radiation Laboratory (NSRL). The replacement of the 35 year old Tandems by a modern injector will be simpler and less costly to operate. Booster injection will become easier and more efficient since one will only need to inject over 1-4 turns, rather than the present 30-60 turn injection. While ion species from the Tandems are limited to those starting as negative ions, the EBIS can provide any ion species, thus allowing the acceleration of all important ion species for the NASA radiobiology program, such as, helium, argon, and neon that are unavailable with the present Tandem injector. Since the desired final charge state can be produced directly in the EBIS, two stripping stages are eliminated, resulting in more stable beam operation,. Finally, this preinjector, coupled to the Booster via a short transport line, will be able to rapidly switch beam species (1 second) to meet the needs of both RHIC and NSRL.simultaneously.

\footnotetext{
*Work supported under the auspices of the US Department of Energy and the National Aeronautics and Space Administration. \# alessi@bnl.gov
}

The project includes the fabrication of an Electron Beam Ion Source for the production of $\mathrm{mA}$-level currents of high charge state heavy ions (ex. $\mathrm{Au}^{32+}$ ) in $\sim 10-40 \mu \mathrm{s}$ pulses, plus the procurement of an RFQ and heavy ion Linac to accelerate ions from EBIS to a final energy of 2 $\mathrm{MeV} / \mathrm{amu}$. A transport line will be fabricated to transport the beam from the output of the Linac to the existing Booster heavy ion injection point.

Performance requirements for the preinjector, including the RFQ and Linac, are given in Table 1.

Table 1: Performance Requirements of the Preinjector

\begin{tabular}{|l|l|}
\hline Species & He to U \\
\hline $\begin{array}{c}\text { Intensity } \\
\text { (examples) }\end{array}$ & $\begin{array}{l}2.7 \times 10^{9} \mathrm{Au}^{32+} / \text { pulse } \\
4 \times 10^{9} \mathrm{Fe}^{20+} / \text { pulse } \\
5 \times 10^{10} \mathrm{He}^{2+} / \text { pulse }\end{array}$ \\
\hline $\mathrm{Q} / \mathrm{m}$ & $\begin{array}{c}\geq 0.16, \text { depending on ion } \\
\text { species }\end{array}$ \\
\hline Repetition rate & $5 \mathrm{~Hz}$ \\
\hline Pulse width & $10-40 \mu \mathrm{s}$ \\
\hline $\begin{array}{c}\text { Switching time } \\
\text { between species }\end{array}$ & 1 second \\
\hline Output energy & $2 \mathrm{MeV} / \mathrm{amu}$ \\
\hline
\end{tabular}

The EBIS has many advantages over other type sources in meeting the requirements of the above applications. An EBIS can produce any type ions - from gas, metals, etc., and is easy to switch species, even pulse-to-pulse, when feeding the trap by injection of singly charged ions from external sources. One has precise control over the charge state produced, and it is easy to produce a distribution peaked at intermediate charge states such as $\mathrm{Au}^{32+}$ or $\mathrm{U}^{45+}$. One has control over pulse width, extracting a fixed charge, so one can better match synchrotron requirements. EBIS produces a narrow charge state distribution $(\geq 20 \%$ in the desired charge state), so there is less of a space charge problem in the extraction and transport of the total current. Finally, the source is reliable, and has excellent pulse-to-pulse stability, and long lifetime.

Requirements for the RHIC EBIS are the following:

\begin{tabular}{|l|l|}
\hline $\begin{array}{l}\text { Output Charge } \\
\text { (single charge state): }\end{array}$ & $\geq 1.1 \times 10^{11}$ charges \\
\hline Ion output $\left(\mathrm{Au}^{32+}\right.$ ): & $3.4 \times 10^{9}$ particles/pulse \\
\hline $\mathrm{Q} / \mathrm{m}$ & $\begin{array}{l}\geq 0.16, \text { depending } \\
\text { on ion species }\end{array}$ \\
\hline $\begin{array}{l}\text { Beam current } \\
\text { (single charge state): }\end{array}$ & $\begin{array}{l}1.7-0.42 \mathrm{~mA} \\
\text { Pulsed, } 10-40 \mu \mathrm{S}, 5 \mathrm{~Hz}\end{array}$ \\
\hline Output energy: & $17 \mathrm{keV} / \mathrm{amu}$ \\
\hline Emittance (Au): & $\begin{array}{l}\sim 0.35 \pi \mathrm{mm} \mathrm{mrad} \\
(\text { norm, } 90 \%)\end{array}$ \\
\hline $\begin{array}{l}\text { Switching times: } \\
\text { Injection-Extraction } \\
\text { Between species }\end{array}$ & $\begin{array}{l}\leq 1 \mathrm{~ms} \\
1 \mathrm{~second}\end{array}$ \\
\hline
\end{tabular}




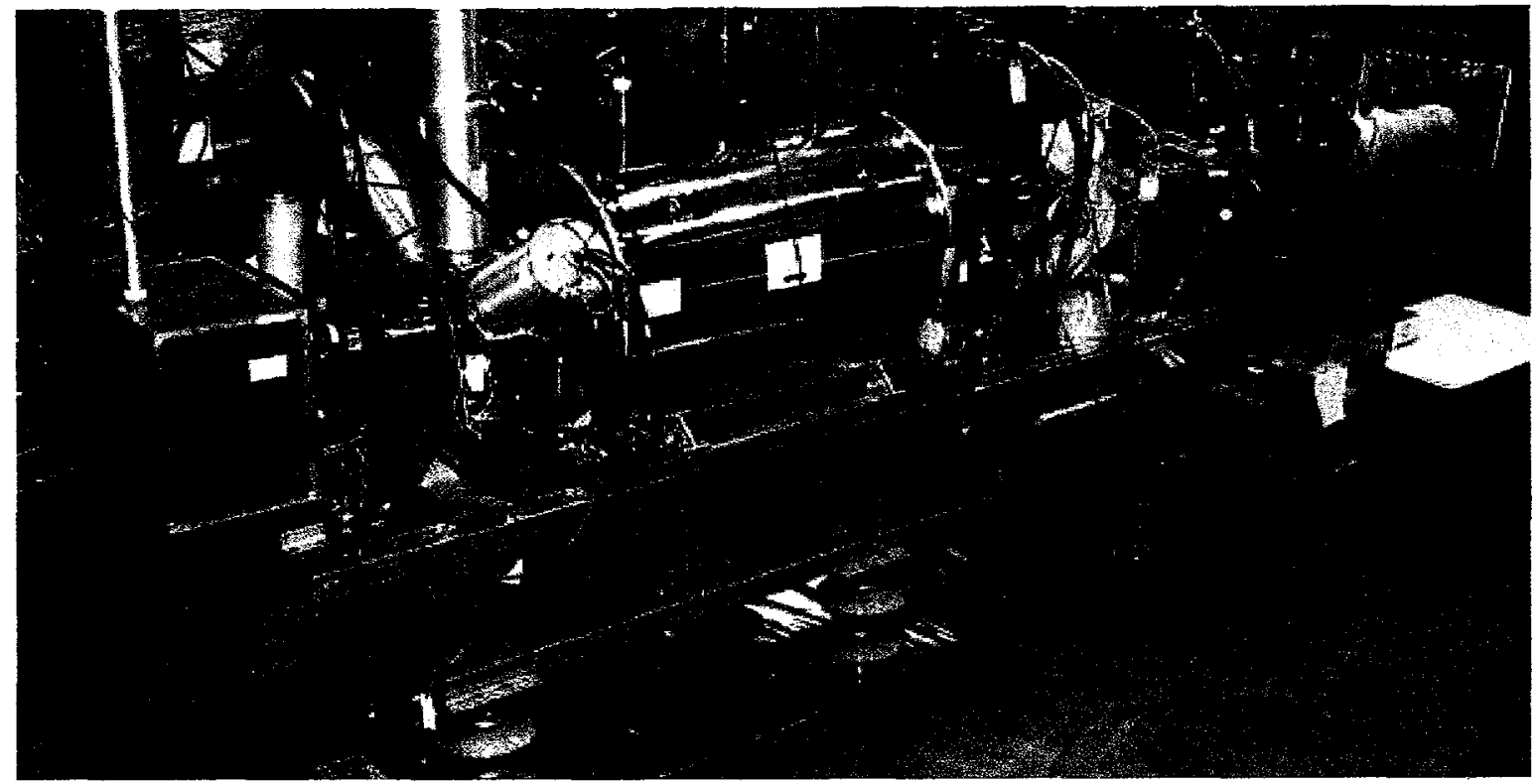

Figure 1: Photo showing the Test EBIS on the high voltage platform, and extraction to time-of-flight diagnostic .

\section{PERFORMANCE OF THE TEST-EBIS}

The Test EBIS, built to demonstrate all essential features of an EBIS meeting RHIC requirements, is shown in Figure 1. This half-trap length $(72 \mathrm{~cm}$, halfyield), full power electron beam prototype is described in detail in [1]. The following are some key features and results.

\section{Electron Beam}

An IrCe cathode, from BINP, Novosibirsk [2], is now routinely used on the Test EBIS, and electron beams up to $10 \mathrm{~A}$, and $100 \mathrm{~kW}$ peak power dissipation on the electron collector have been propagated with losses less than $1 \mathrm{~mA}$. The gun perveance is $1.3 \times 10^{-6} \mathrm{~A} / \mathrm{V}^{3 / 2}$. At our design electron current of $10 \mathrm{~A}$, the IrCe cathodes have expected lifetimes of $\sim 20,000$ hours, several times longer than the $\mathrm{LaB}_{6}$ cathodes previously used.

\section{Ion Output}

$\mathrm{Au}^{32+}$ has been produced in less than $35 \mathrm{~ms}, \mathrm{Ne}^{8+}$ in $18 \mathrm{~ms}, \mathrm{~N}^{5+}$ in $4 \mathrm{~ms}$, and $\mathrm{Cu}^{15+}$ in $15 \mathrm{~ms}$. Charge state vs. confinement time agrees with calculations. With external ion injection, $3.5 \times 10^{11}$ charges/pulse of $\mathrm{Au}$ ions, and $\geq 2 \times 10^{11}$ charges/pulse of $\mathrm{Ne}, \mathrm{N}$, and $\mathrm{Cu}$ have been achieved. In all cases our goal of extracting charge of $50 \%$ of the trap capacity has been exceeded. The above yields can be extracted in pulses of 10-20 $\mathrm{s}$ FWHM, resulting in extracted currents for these ions of several $\mathrm{mA}$ 's. Examples of ion pulses and charge state distributions are shown in Figures 2 and 3.
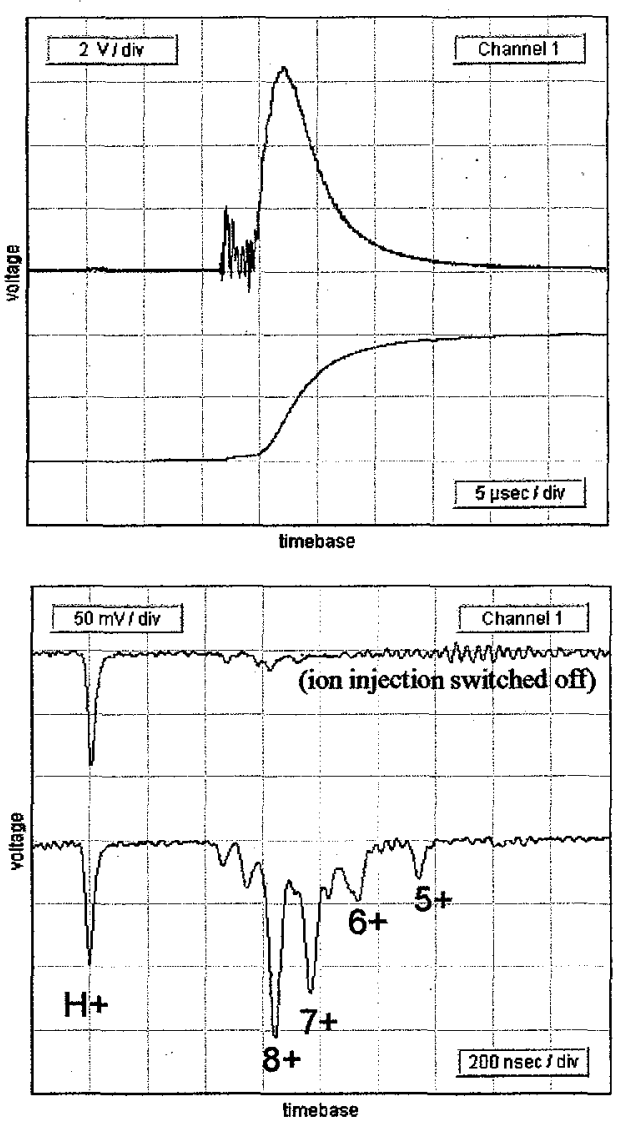

Figure 2: Neon ions produced with a $6.8 \mathrm{~A}$ electron beam and $18 \mathrm{~ms}$ confinement, $6.3 \mathrm{~mA}$ peak; $2.4 \mathrm{x}$ $10^{11}$ charges/pulse. 

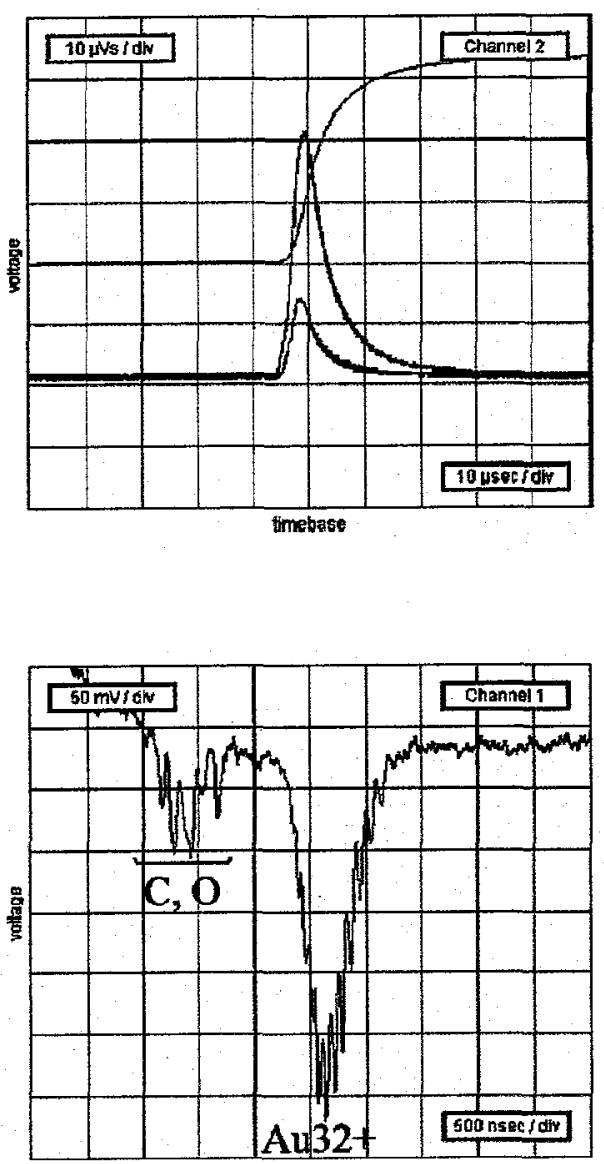

Figure 3: Au ions produced with a 6.8 A electron beam and $36 \mathrm{~ms}$ confinement, $4.0 \mathrm{~mA}$ peak; $2.0 \mathrm{x}$ $10^{11}$ charges/pulse. Charge state distribution peaked around $\mathrm{Au}^{32+}$

\section{High Voltage Operation}

The Test EBIS has now been installed on a platform isolated for $100 \mathrm{kV}$. The EBIS only has to be at high voltage during the $<50 \mu$ s ion extraction time, so pulsing of the high voltage reduces the likelihood of breakdowns, and allows the external ion sources and injection lines to reside at laboratory potential. A $100 \mathrm{kV}$ pulsed power supply has been fabricated. Operation of the Test EBIS at the maximum required $80 \mathrm{kV}$ extraction has been very successful. There is no change in performance observed when the platform voltage is pulsing, and no voltage breakdowns are observed.

\section{Emittance}

A normalized, rms emittance of $0.1 \pi \mathrm{mm}$ mrad has been measured for a $1.7 \mathrm{~mA}$ Au beam extracted from the EBIS. For lighter ion species and higher currents, emittances increase to $\sim 0.3 \pi \mathrm{mm}$ mrad. (Since there is no separation of beam components, the emittance of all charge states were measured; individual charge state emittance could be smaller). Normalized rms emittances were constant whether measured with the platform at ground potential, or with up to $80 \mathrm{kV}$ acceleration (i.e. 18 to $98 \mathrm{keV}$ ).

\section{Seeding the EBIS trap}

We rely on external ion injection to provide most ion species. In this manner, the EBIS functions purely as a charge state multiplier. One can easily change species and charge state on a pulse to pulse basis, and there is virtually no contamination or memory effect. To date, we have operated the EBIS successfully with external ion injection from a Metal Vapor Vacuum Arc Source [3], a Hollow Cathode Ion Source [4], and a Liquid Metal Ion Source [5]. In addition, for beams such as helium, we have used standard gas injection.

\section{STATUS OF RHIC EBIS HARDWARE}

Other than a straightforward scaling of the length of the ion trap, the parameters chosen for the RHIC EBIS do not deviate in any significant way from those demonstrated in the very successful prototype Test EBIS described above. An electron beam current of $10 \mathrm{~A}$ and trap length of $1.5 \mathrm{~m}$ are sufficient to produce the required total extracted ion charge of $5.5 \times 10^{11}$. A schematic of the RHIC EBIS is shown in Figure 4.

\section{Electron Gun}

The performance required for the RHIC EBIS can be achieved with the $10 \mathrm{~A}$ electron gun already in use. Nevertheless it is desirable to have a safety margin with electron beam current for EBIS operation at $10 \mathrm{~A}$ and some prospects for increase of output ion intensity in the future, and indeed, with this IrCe cathode one has the possibility of increasing emission and producing an electron current up to $20 \mathrm{~A}$. We have such a design of the electron gun and collector which would allow a possible future increase of electron current in RHIC EBIS to $20 \mathrm{~A}$. To reach electron current of $\mathrm{I}_{\mathrm{el}}=20$ A with existing $40 \mathrm{kV}$ anode power supplies the perveance of the gun is doubled relative to our present gun. The $\mathrm{IrCe}$ cathode can provide emission current density $40 \mathrm{~A} / \mathrm{cm}^{2}$, with an expected lifetime at this density of several thousand hours [2]. The design is based on the inverted magnetron geometry of our existing electron gun of Novosibirsk design, which produces a laminar electron beam, allowing operation in a wide range of electron current, potential and magnet field distributions. It also allows substantial deceleration of the electron beam in the ion trap and electron collector regions. The cathode is immersed in a magnetic field of approximately $0.14 \mathrm{~T}$. The perveance of this gun is $\sim 2.5 \cdot 10^{-6} \mathrm{~A} / \mathrm{V}^{3 / 2}$.

\section{Electron Collector}




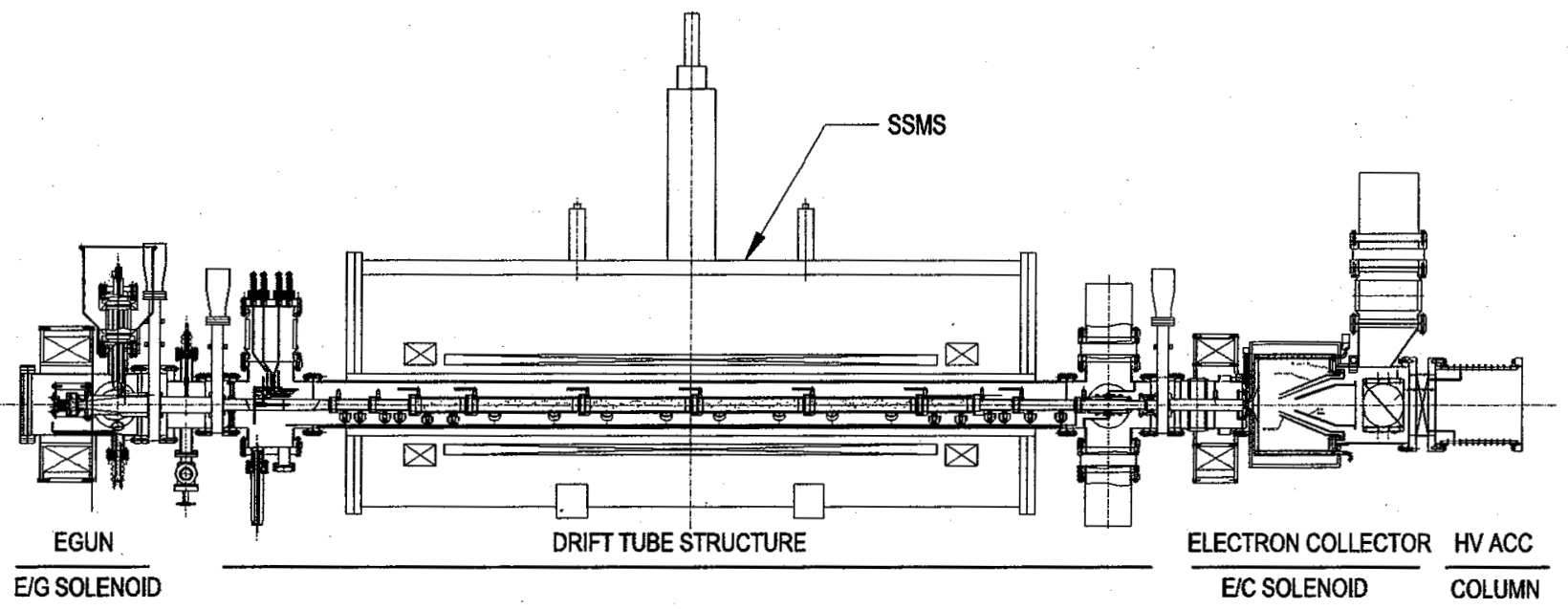

Figure 4: Schematic of the EBIS for RHIC.

The electron collector for the EBIS, shown schematically in Fig, 5 , is presently being fabricated. It is required to handle a $\sim 50 \mathrm{~ms}, 5 \mathrm{~Hz}$ pulsed electron beam with current up to $20 \mathrm{~A}$ and collection energy up to 15 $\mathrm{keV}$. The electron optics, cooling structure and material of the electron collector were optimized to reduce both the average temperature of the inner surface and amplitude of its variations during the operation cycle. The maximum heat load on the inner surface for electron beam current 20 $\mathrm{A}$ is $\sim 350 \mathrm{~W} / \mathrm{cm}^{2}$ during the pulse, and averaged over the area being hit, is $\sim 200 \mathrm{~W} / \mathrm{cm}^{2}$ during the pulse. The collector material is Hycon $3 \mathrm{HP}$ (Brush-Wellman). This high conductivity $\mathrm{BeCu}$, was chosen since it provides longer fatigue lifetime. However, due to difficulties this material is presenting during electron beam welding, we are also beginning the fabrication of a second collector using a zirconium chromium copper alloy.

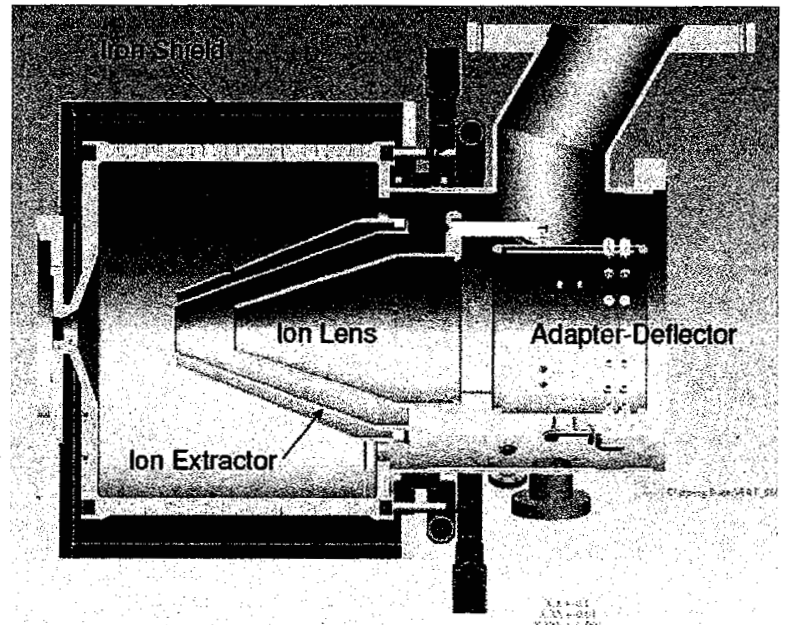

Figure 5: Electron collector for the RHIC EBIS.

\section{Superconducting Solenoid}

The superconducting solenoid is a major component of the EBIS. For RHIC, the straightforward doubling of the trap length by installing a longer superconducting solenoid is required. The solenoid will have a coil length of $1.9 \mathrm{~m}$, a warm bore diameter of $204 \mathrm{~mm}$, and a peak field of $6 \mathrm{~T}$. This solenoid is being fabricated by ACCEL [6], and delivery is now expected in July, 2007.

\section{PROJECT STATUS}

Components for the RHIC EBIS are now being fabricated. A prototype of the low energy beam transport section, matching beam from the EBIS into the RFQ, has been fabricated and is now being tested [ref these proceedings].

A $100 \mathrm{MHz}$, 4-rod RFQ will accelerate the beam from an input energy of $17 \mathrm{keV} / \mathrm{amu}$, to $300 \mathrm{keV} / \mathrm{amu}$. This will be followed by a $100 \mathrm{MHz}$ IH linac for acceleration to the final energy of $2 \mathrm{MeV} / \mathrm{amu}$. The RFQ and linac are both being designed and fabricated by the Institute of Applied Physics, Frankfurt [7]. The $400 \mathrm{~kW}$ rf amplifiers for these structures are being manufactured by Continental Electronics [8].

Testing of the RFQ with beam from the Test EBIS is scheduled for early in 2008. First testing of the RHIC EBIS source is presently planned for the spring of 2008 .

\section{REFERENCES}

[1] E.N. Beebe, et.al., Journal of Physics:Conference Series 2 (2004) 164-173.

[2] G. Kuznetsov, Nuclear Instruments \& Methods in Physics Research A 340, 1994, pp.204-208.

[3] I.G Brown, et.al., Rev. Sci. Instrum. 65 (1994) 1260.

[4] B. Visentin, et.al., Physica Scripta T71 (1997) 204206.

[5] A. Pikin, et.al., Rev. Sci. Instrum. 77, p. 03 A909 1-3 (2006).

[6] ACCEL Instruments GmbH, Bergisch Gladbach, Germany.

[7] A. Schempp, et.al., "RFQ and IH accelerators for the new EBIS injector at BNL", these proceedings.

[8] Continental Electronics Corporation, Dallas, TX. 